\title{
Overpressure Processing Bi2223/Ag Tapes
}

\author{
M.O. Rikel, R.K. Williams, X.Y.Cai, A.A. Polyanskii, J. Jiang, D. Wesolowski, E.E. Hellstrom, \\ D.C. Larbalestier, K. DeMoranville, and G.N. Riley, Jr.
}

\begin{abstract}
We report on the effect of overpressure processing on the electromagnetic properties and microstructure of monocore and multifilamentary $\mathrm{Bi} 2223 / \mathrm{Ag}$ tapes. Samples at various stages of the usual thermo-mechanical processing for Bi2223/Ag tapes (from as-rolled to fully processed) were subjected to annealing at $815-820^{\circ} \mathrm{C}$ for $18-108 \mathrm{~h}$ in a static $\mathrm{Ar}$ $+\mathrm{O}_{2}$ atmosphere at the overall pressure $17.5 \pm 0.5 \mathrm{MPa}\left(\mathrm{pO}_{2}=\right.$ 0.003-0.02 MPa). Density measurements, microhardness tests, and SEM examination of polished sections reveal a notable densification of overpressure-processed samples. For partly reacted (so called HT1) samples, we found that overpressure processing for $36 \mathrm{~h}$ is sufficient to densify the $\mathrm{Bi2223}$ core from $70 \pm 5$ to $87 \pm 4 \%$ theoretical density and increase self-field $J_{\mathrm{c}}(77 \mathrm{~K})$ from $8 \pm 1$ to $30 \pm 5 \mathrm{kA} / \mathrm{cm}^{2}$ The results show that onestep processing of $\mathrm{Bi} 2223 / \mathrm{Ag}$ tapes is possible.
\end{abstract}

Index Terms-Bi2223/Ag tapes, Critical currents, MagnetoOptical studies, Overpressure processing

\section{INTRODUCTION}

O ILVER sheathed $(\mathrm{Bi}, \mathrm{Pb})_{2} \mathrm{Sr}_{2} \mathrm{Ca}_{2} \mathrm{Cu}_{3} \mathrm{O}_{\mathrm{x}}(\mathrm{Bi} 2223 / \mathrm{Ag})$ tapes are presently the only high-temperature superconductors (HTS) available in long lengths for application at liquidnitrogen temperatures. Multifilamentary tapes with self-field critical current densities $J_{\mathrm{c}}>30 \mathrm{kA} / \mathrm{cm}^{2}$ and excellent $J_{\mathrm{c}}$ homogeneity from the scale of $100 \mu \mathrm{m}$ to hundreds of meters are routinely produced by several manufacturers [1]. Despite the fact that all prototype devices for power applications are presently based on $\mathrm{Bi} 2223 / \mathrm{Ag}$ tapes, there is a widespread concern that $\mathrm{Bi} 2223$ has neither the performance nor the low cost needed to make HTS applications generally attractive. Part of this concern is the slow increase in $J_{\mathrm{c}}$ of $\mathrm{Bi} 2223 / \mathrm{Ag}$ conductors during the past five years, which is believed to be due to intrinsic limitations of the present processing route.

The $\mathrm{Bi} 2223 / \mathrm{Ag}$ conductors are prepared by the oxidepowder-in-tube (OPIT) method and subjected to a thermomechanical processing in order to form and align the $\mathrm{Bi} 2223$

Manuscript received September 18, 2000. This work was supported by the Department of Energy Efficiency and Renewable Energy and also benefited from partial support from the National Science Foundation-MRSEC.

R.K. Williams is with the Oak Ridge National Laboratory, Oak Ridge, TN 37831

M.O. Rikel, X.Y. Cai, A.A. Polyanskii, J. Jiang, D. Wesolowski, E.E. Hellstrom, and D.C. Larbalestier are with the Applied Superconductivity Center, University of Wisconsin Madison, Madison, WI 53705, USA (contact author E.E. Hellstrom, e-mail: hellstrom@engr.wisc.edu).

M,O. Rikel is on leave from Lebedev Physical Institute, Moscow, Russia.

K. DeMoranville and G.N. Riley, Jr. are with The American Superconductor Corp., Westborough, MA 01581, USA core. The usual thermo-mechanical processing consists of two heat treatment (HT) steps separated by an intermediate rolling (IR) step. During the first HT step (HT1), about 80\% Bi2223 is formed from the precursor powder (Bi2212+ other cuprate phases). The reaction is usually accompanied by retrograde densification (the density decreases by $10-20 \%$ as compared to the as-rolled state) [2]. The IR step is needed to densify the Bi2223 core, and the HT2 step is intended to complete Bi2212 to Bi2223 conversion and heal microcracks produced during IR [1]. This thermo-mechanical processing is inherently compromised by its inability to remove porosity without introducing cracks. The result of this compromise is that even the best fully processed tapes contain 10-25\% distributed pores [2], [3] and only 5-20\% of the cross-section actually carries current [4], [5]. The real potential of $\mathrm{Bi} 2223 / \mathrm{Ag}$ tapes was demonstrated by recent magneto-optical (MO) magnetization measurements [6] in monocore Bi2223 tapes that revealed regions with local $J_{\mathrm{c}} \approx 180 \mathrm{kA} / \mathrm{cm}^{2}$, a value that is still 5 times smaller than $J_{\mathrm{c}}$ in high-quality Bi2223 thin films [7].

Hot isostatic pressing (HIP) is one of the obvious possibilities to overcome the problem of porosity and cracks in Bi2223 tapes. Earlier work showed that bulk 2223 is stable in its own atmosphere (pellets encapsulated in a PYREX glass) under $150 \mathrm{MPa}$ and $650-870^{\circ} \mathrm{C}$ and can be densified to $95 \%$ theoretical density [8]-[10]. To apply HIP to Bi2223/Ag tapes, one has to solve the problems of isolating the core from the outer atmosphere and controlling very small levels of $\mathrm{pO}_{2}$ in the HIP system to avoid decomposition of $\mathrm{Bi2223}$. To our knowledge, application of HIP to processing Bi2223/Ag tapes was reported to be successful only at low temperature $\left(700^{\circ} \mathrm{C}\right.$ and $2 \mathrm{~h}$ ) for short times under $150 \mathrm{MPa} \mathrm{Ar}$, which restored a self field $J_{\mathrm{c}}$ of $0.5 \mathrm{kA} / \mathrm{cm}^{2}$ [11]. Pure Ar cannot be used at higher temperature because the $\mathrm{Bi} 2223$ will decompose in this low $\mathrm{pO}_{2}$ atmosphere [12].

In this work, we explore the possibility of using overpressure processing to densify the $\mathrm{Bi} 2223$ in Ag-sheathed tapes at temperatures where 2223 forms. Because of the low applied pressure $\sim 20 \mathrm{MPa}$ used in this work, we prefer the term overpressure (OP) instead of HIP. Our ultimate goal is to develop a one-step heat treatment that produces a dense, well-aligned $\mathrm{Bi} 2223$ microstructure. In this paper, we report the first positive results of our work. We found that applying an overpressure of only $17.5 \mathrm{MPa}$ for $36 \mathrm{~h}$ at $815^{\circ} \mathrm{C}$ is sufficient to densify the Bi2223 core. For HT1 samples subjected to OP annealing, the $77 \mathrm{~K}$ self-field $J_{c}$ values are comparable to those of samples produced using the usual thermo-mechanical processing. 


\section{EXPERIMENTAL PROCEDURES}

Most of the data reported below were obtained using 3-4 $\mathrm{cm}$ long samples of 85-filament tapes after different stages of thermo-mechanical processing (as-rolled, after HT1, after IR, and fully processed) made at American Superconductor Corp. We also studied short samples of monocore tape prepared at UW from fully reacted ( $95 \% \mathrm{Bi} 2223)$ powder with overall composition $\mathrm{Bi}_{1.8} \mathrm{~Pb}_{0.33} \mathrm{Sr}_{1.87} \mathrm{Ca}_{2.0} \mathrm{Cu}_{3.0} \mathrm{O}_{\mathrm{x}}$ (Merck).

To isolate the $\mathrm{BSCCO}$ core from the high-pressure atmosphere, the ends of the tape samples were sealed by wrapping them in a $40 \mu \mathrm{m}$-thick $\mathrm{Ag}$ foil, pressing under a pressure of $400 \mathrm{MPa}$, and diffusion welding by annealing at $800^{\circ} \mathrm{C}$ for $3 \mathrm{~h}$ in $7.5 \% \mathrm{O}_{2}$ (balance $\mathrm{N}_{2}$ ).

The overpressure experiments were carried out at ORNL in an overpressure furnace with a static atmosphere [13]. The high-temperature, high-pressure vessel of the furnace was made of Inconel 617 tube $(1.7 \mathrm{~cm} \mathrm{ID,} 4.8 \mathrm{~cm} \mathrm{OD)}$. For safety reasons, the total maximum pressure at the temperatures of interest $\left(815-830^{\circ} \mathrm{C}\right)$ was limited to $P_{\text {total }} \leq 18 \mathrm{MPa}$. Samples were put in a closed end of the quartz tube $(8 \mathrm{~mm}$ ID) that was placed in the Inconel tube. Because of the very limited space in the furnace (a $5 \mathrm{~cm}$ long hot zone), only 4-6 tape samples could be stacked together. They were separated from one another by an inert powder. In our first runs, we used $\mathrm{CaZrO}_{3}$ powder. We found, however, that this powder contained $1-2 \% \mathrm{CaCO}_{3}$ that decomposes above $600^{\circ} \mathrm{C}$, and in the static atmosphere furnace, the trapped $\mathrm{CO}_{2}$ reacted with $\mathrm{Bi} 2223: \mathrm{SrCO}_{3}$ particles up to $20 \mu \mathrm{m}$ in diameter were found by SEM and XRD in the outer filaments of the tapes after OP annealing at $820^{\circ} \mathrm{C}$ for $64 \mathrm{~h}$. We also learned from the nonuniform distribution of $\mathrm{SrCO}_{3}$ particles between the outer and inner filaments of the reacted tape that the outer $\mathrm{Ag}$ sheath of multifilamentary tapes might contain microcracks. In the next runs, we wrapped each tape in a $100-\mu \mathrm{m}$ thick $\mathrm{Ag}$ foil and electron-beam welded it. We used $\mathrm{SrZrO}_{3}$ powder to separate the samples from one another.

Overpressure annealing was carried out at 815 and $820^{\circ} \mathrm{C}$ for $18-108 \mathrm{~h}$ at $P_{\text {total }}=17.5 \pm 0.5 \mathrm{MPa}$. The initial oxygen partial pressure of $\mathrm{pO}_{2}=0.008-0.021 \mathrm{MPa}$ was achieved in the system by flushing the furnace with pure $\mathrm{Ar}(99.999 \%)$ at $\sim 12 \mathrm{MPa}$ 4-5 times, then adding the necessary amount of an $\mathrm{Ar}+20 \% \mathrm{O}_{2}$ mixture, and pressurizing the furnace to $\sim 12$ $\mathrm{MPa}$ with pure $\mathrm{Ar}$ at room temperature. The final pressure $\sim 17.5 \mathrm{MPa}$ was reached during heating. The temperature was measured with a $\mathrm{Pt}-\mathrm{PtRh}$ thermocouple and is accurate to within $\pm 2^{\circ} \mathrm{C}$.

After the first $\mathrm{OP}$ runs at $820^{\circ} \mathrm{C}$ that began with an initial $p \mathrm{O}_{2}=0.008 \mathrm{MPa}$, we found that it is very difficult to maintain the proper $p \mathrm{O}_{2}$ level in the furnace, because of the slow oxidation of the Inconel 617 tube. By putting $3 \mathrm{~g}$ of sintered $0.5 \mathrm{Bi} 2223+0.5 \mathrm{Bi} 2212$ pellets close to the hot zone, we were able to maintain $\mathrm{pO}_{2}$ in the range 0.012-0.005 $\mathrm{MPa}$ for $36 \mathrm{~h}$ at $815^{\circ} \mathrm{C}$. The initial and final $\mathrm{pO}_{2}$ was measured by mass-spectrometry. Most of the results reported below are obtained using these conditions.

Samples were characterized by $I_{\mathrm{c}}$ measurements in magnetic fields perpendicular to the broad face of the tapes. The $I_{\mathrm{c}}$ was determined from extended voltage-current characteristics using a $1 \mu \mathrm{V} / \mathrm{cm}$ criterion. Microstructure and phase composition were studied using SEM (JEOL JSM6100) of polished sections and XRD (STOE, $\mathrm{Cu} \mathrm{K}$ 年adiation) of the sample surface after etching off the outer Ag sheath. The same samples were used for plan-view magneto-optical (MO) imaging. The mass density of individual filaments extracted from the samples was calculated from the weight (microbalance Cahn C-35), length, and area of the filament cross section. The Vickers microhardness of the Bi2223 core in monocore tapes was measured using a LECO M-400-G tester $(10 \mathrm{~g}, 10 \mathrm{~s})$.
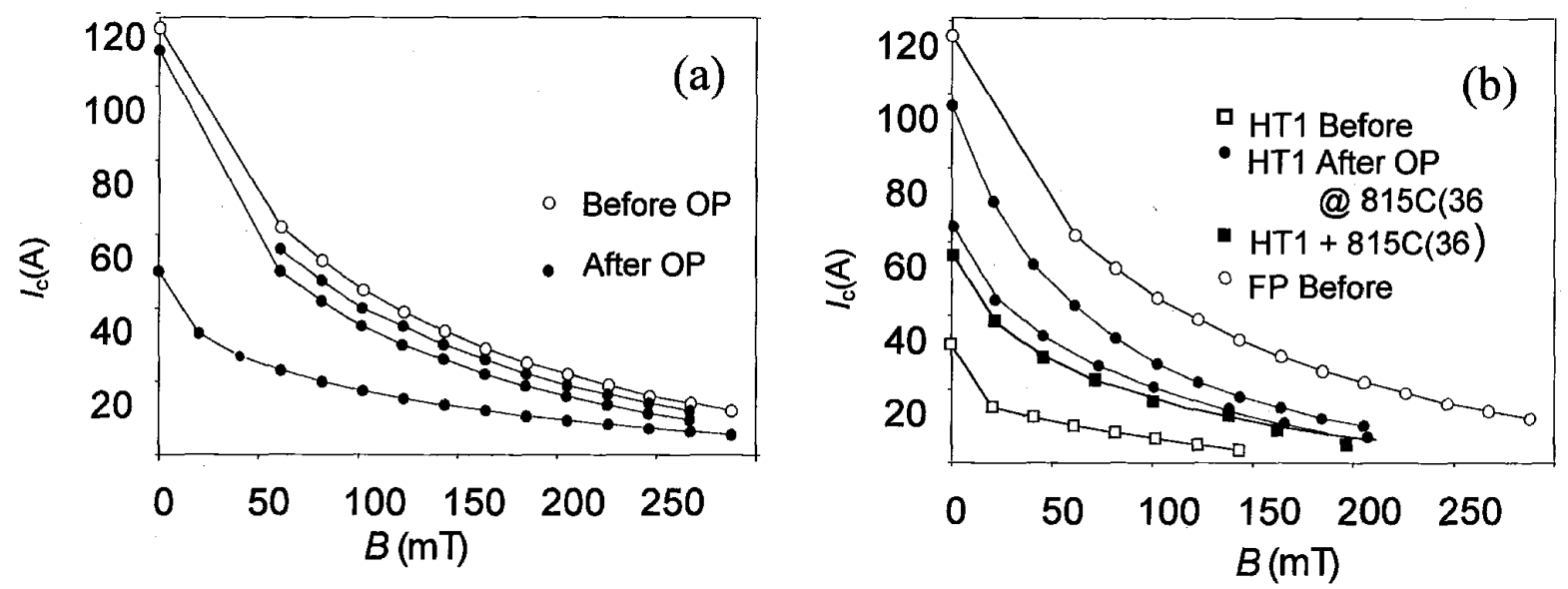

Fig. 1. Magnetic-field dependence of $I_{\mathrm{c}}$ in (a) fully processed Bi2223/Ag tapes and (b) HT1 tapes before and after OP annealing at $815^{\circ} \mathrm{C}$ for $36 \mathrm{~h}\left(P_{\text {total }}=17.5\right.$ $\mathrm{MPa}, p \mathrm{O}_{2}=0.012-0.005 \mathrm{MPa}$ ) and after an equivalent heat treatment with $P_{\text {total }}=0.1 \mathrm{MPa}$ and $p \mathrm{O}_{2}=0.008 \mathrm{MPa}$. FP fully processed. 

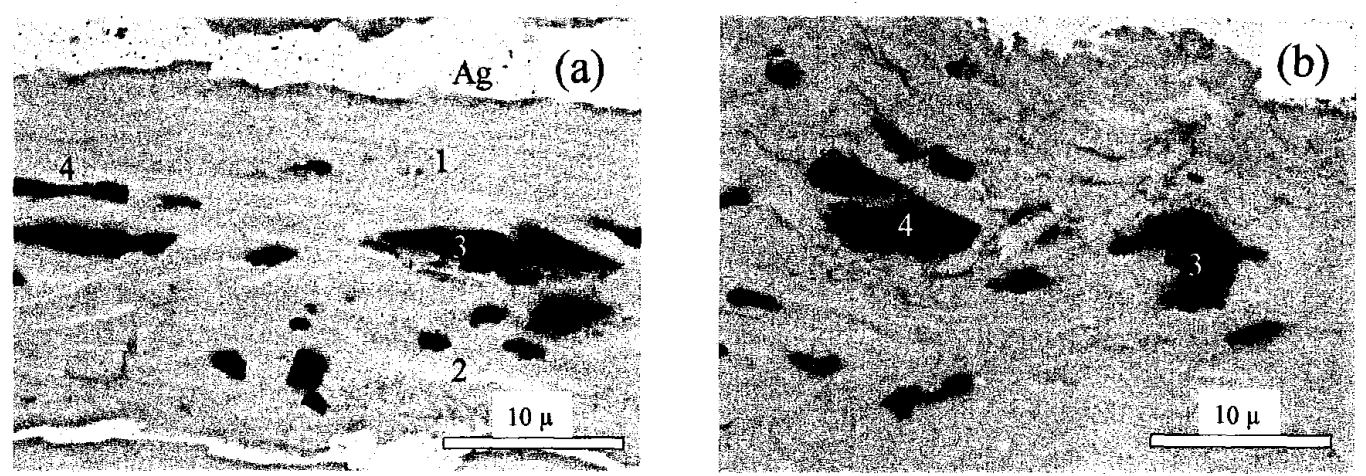

Fig. 2. Microstructure of $\mathrm{HT} 1$ sample (a) after OP annealing at $815^{\circ} \mathrm{C}$ for $36 \mathrm{~h}\left(P_{\text {total }}=17.5 \mathrm{MPa}, p \mathrm{O}_{2}=0.010-0.006 \mathrm{MPa}\right)$ and (b) after equivalent annealing, but at $P_{\text {total }}=0.1 \mathrm{MPa}, p \mathrm{O} 2=0.008 \mathrm{MPa}$. Phases: (1) 2223, (2) 2212, (3) 14:24 AEC, (4) 2:1 AEC.

\section{RESULTS}

\section{A. Multifilamentary Tapes}

Fig. 1a compares the $I_{\mathrm{c}}(H)$ curves in fully processed tapes before and after OP annealing, where no improvement is observed. XRD data show that OP processed tapes experience some decomposition (the fraction of $\mathrm{Bi} 2212$ increased from 3 \pm 1 to $6 \pm 2 \%$ ) due to improper $p \mathrm{O}_{2}$. The decomposition was also seen in SEM studies: the amount of second phases $\left[(\mathrm{Ca}, \mathrm{Sr})_{2} \mathrm{CuO}_{3}\right.$ and $\left.(\mathrm{Pb}, \mathrm{Bi})_{3}(\mathrm{Sr}, \mathrm{Ca})_{5} \mathrm{Cu}_{1} \mathrm{O}_{\mathrm{x}}\right]$ increased by a factor of 1.5 , which together with the remaining 2212 constituted $\sim 10$ vol $\%$ of the filaments.

In Fig. $1 \mathrm{~b}$, we present the $I_{\mathrm{c}}(H)$ data for HT1 samples before and after OP annealing and after a similar annealing but at normal pressure $\left(P_{\text {total }}=0.1 \mathrm{MPa}, p \mathrm{O}_{2}=0.008 \mathrm{MPa}\right)$. Although there is a certain irreproducibility in the results, the average $I_{c}$ values of OP annealed samples are higher. In the best OP sample, the $I_{c}$ is about $80 \%$ of the value for the optimized fully processed sample with self-field $J_{c}(77 \mathrm{~K})=35$ $\mathrm{kA} / \mathrm{cm}^{2}$. Note that because of the improper $\mathrm{pO}_{2}$ control, the amount of residual 2212 in this particular sample was reduced to only $7 \pm 2 \%$, i.e., twice as large as in the optimized fully processed tape and in the sample annealed $36 \mathrm{~h}$ at $815^{\circ} \mathrm{C}$ without OP. Comparison of microstructures in the HT1 samples processed with and without OP (Fig. 2) shows that $O P$ annealing produces qualitatively denser material.

Measurements of the mass density of individual filaments confirmed the qualitative conclusion of the SEM work. The average mass density of the filaments after OP annealing is $5.5 \pm 0.1 \mathrm{~g} / \mathrm{cm}^{3}$ compared to $4.4 \pm 0.3 \mathrm{~g} / \mathrm{cm}^{3}$ before OP.

Fig. 3 compares the MO images of HT1 samples after OP annealing and after equivalent annealing, but at $P_{\text {total }}=0.1$ $\mathrm{MPa}, p \mathrm{O}_{2}=0.008 \mathrm{MPa}$. The average magnetization level is significantly larger in the sample after OP (cf. Figs. 3a and 3b). However, the flux penetration pattern (Fig. 3c) is very similar to that after annealing at the normal pressure (Fig. 3a).

XRD studies of both HT1 and fully processed samples before and after OP show a noticeable deterioration of grain alignment during OP. The FWHM of the rocking curves of the 0024 reflection increased by about $2^{\circ}$ (e.g., from $\sim 14$ to $\sim 16^{\circ}$ for HT1 samples).

\section{B. Monocore Tape with Reacted Bi2223 powder.}

Vickers microhardness (HV) was measured in the monocore tape made with fully reacted $\mathrm{Bi} 2223$ powder that had been OP processed at $815^{\circ} \mathrm{C}$ for $18 \mathrm{~h}$ and after annealing at $815^{\circ} \mathrm{C}$ for $36 \mathrm{~h}$ at normal pressure $\left(P_{\text {total }}=0.1 \mathrm{MPa}, p \mathrm{O}_{2}=\right.$ $0.008 \mathrm{MPa})$. The average $\mathrm{HV}$ is dramatically improved from $104 \pm 3$ to $187 \pm 2 \mathrm{~kg} / \mathrm{mm}^{2}$ by applying overpressure. Because the size of the indentation trace $(\sim 10 \mu \mathrm{m})$ is much larger than the size of second-phase particles $(\sim 1-5 \mu \mathrm{m})$, this increase can be completely attributed to the higher density of the $\mathrm{Bi} 2223$ core.

No supercurrent was measured at $77 \mathrm{~K}$ in the tape annealed at normal pressure. The tape subjected to the OP annealing has a very low $J_{c}(77 \mathrm{~K}, 0 \mathrm{~T}) \approx 50 \mathrm{~A} / \mathrm{cm}^{2}$. This can be related to the poor texture in these samples. The FWHM of the rocking curve of the 0024 reflection was $27.3 \pm 0.6^{\circ}$.

\section{DISCUSSION}

We processed multifilamentary and monocore $\mathrm{Bi} 2223 / \mathrm{Ag}$ tapes under moderate overpressure, and studied the effect of such processing on transport properties, microstructure, and mass density.

Our experiments were carried out in a furnace with a static atmosphere and oxygen-consuming environment. This imposed very rigid constraints on the duration of $O P$ annealing. We were able to maintain $p \mathrm{O} 2$ in the range 0.012 $0.005 \mathrm{MPa}$, where $\mathrm{Bi} 2223$ is stable at $815^{\circ} \mathrm{C}$ for $36 \mathrm{~h}$. Working in this $p \mathrm{O}_{2}$ range suppressed severe decomposition of 2223, but did not completely eliminate it. In fully processed samples, about $5 \%$ of the 2223 decomposed during OP annealing, and in HT1 samples, the formation kinetics of 2223 seems to be slower than for the usual heat treatment with constant $\mathrm{pO}_{2}=0.008 \mathrm{MPa}$. This might affect the $I_{\mathrm{c}}$ performance of the samples. Nevertheless, the $I_{\mathrm{c}}$ level reached in these OP experiments is quite encouraging, particularly for HT1 samples. Although, we did not obtain high $I_{\mathrm{c}}$ by OP annealing as-rolled samples, the positive results for HT1 

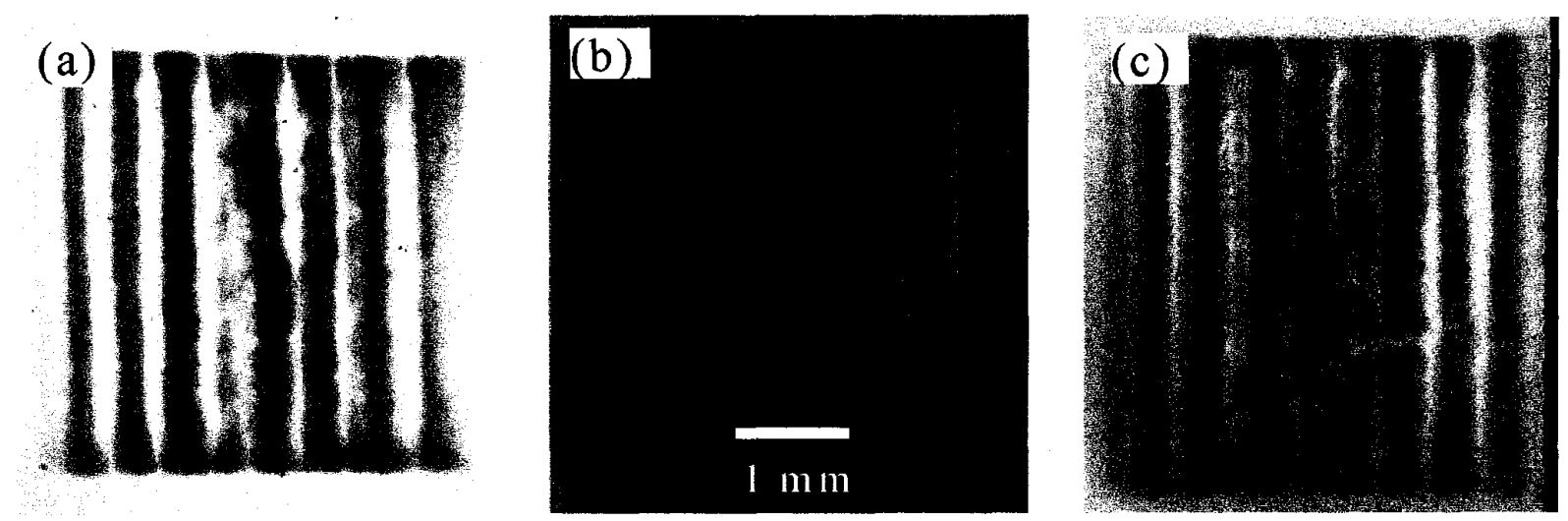

Fig. 3. MO images taken in the ZFC mode at $T=15 \mathrm{~K}$ and $B=80 \mathrm{mT}$ of $\mathrm{HT} 1$ samples after annealing at $815^{\circ} \mathrm{C}$ for $36 \mathrm{~h}$ (a) without and (b, c) with $\mathrm{OP}$ processing. Images (a) and (b) were obtained under exactly the same optical conditions. Image (c) was obtained by changing optical conditions to better resolve the flux-penetration pattern.

samples suggest that one-step processing of $\mathrm{Bi} 2223 / \mathrm{Ag}$ tapes is possible.

Microstructural observations, density measurements, and microhardness data give convincing evidence that applying moderate overpressure of $17.5 \mathrm{MPa}$ produces noticeable densification of the Bi2223 core. However, longer annealing time and/or higher external pressures are needed to complete densification.

The same conclusion can be made based on the MO data. Changes in the average magnetization revealed from $\mathrm{MO}$ images are consistent with the $I_{\mathrm{c}}$ measurements. However, very similar flux-penetration patterns in the samples annealed with and without overpressure suggest that cracks, which are a key current-limiting defect, still remain in the samples.

Deterioration of 2223 texture during OP annealing was observed, perhaps due to rumpling on densification. Note that the core densification during the IR step of the usual processing is also accompanied by deterioration of texture [14]. Almost zero $I_{c}$ observed in highly dense Bi2223 monocore tape with very bad texture emphasizes that densification is not sufficient to obtain high $I_{\mathfrak{c}}$. Nevertheless, eliminating porosity is a very necessary step and the results of the present work show that this goal can be attained by OP processing.

\section{ConClusion}

The main result of our studies is that overpressure processing at $815^{\circ} \mathrm{C}$ for $36 \mathrm{~h}$ under a pressure of only 17.5 $\mathrm{MPa}$ is sufficient to densify the $\mathrm{Bi} 2223$ core in multifilamentary tapes from $70 \pm 5$ to $87 \pm 4 \%$ theoretical density. Longer annealing at higher pressures with better controlled oxygen partial pressure is necessary to fully understand the potential of OP processing for fabricating Bi2223/Ag conductors.

\section{ACKNOWLEDGMENT}

We thank Dr. V. Maroni (ANL) for valuable discussions and D.A.Frederick (ORNL) for the help with e-beam welding.

\section{REFERENCES}

[1] P. Vase, R. Flükiger, M. Leghissa, and B. Glowacki, "Current status of high- $T_{\mathrm{c}}$ wire”, Supercond. Sci. Technol., vol. 13, pp. R71-R84, 2000.

[2] B. Wolf, P. Paufler, M. Schubert, C. Rodig, and K. Fischer, "Mass density evolution during manufacturing of Ag-sheathed BPSCCO tapes," Supercond. Sci. Technol., vol. 9, pp. 589-597, 2000.

[3] J. Jiang, X.Y. Cai, J.G. Chandler, D.C. Larbalestier, R.D. Parrella, D. $\mathrm{Yu}, \mathrm{Q}$. Li, M.W. Rupich, and G.N. Riley, Jr., "Correlation of density, porosity, and $J_{c}$ in Ag-clad Bi-2223 tapes," presented at ASC'2000.

[4] X.Y. Cai, A. Polyanskii, Q. Li, G.N. Riley, Jr., and D.C. Larbalestier, "Current-limiting mechanisms in individual filaments extracted from superconducting tapes," Nature, vol. 392, pp. 906-909, 1998.

[5] K.H. Müller, C. Andrikidis, J. Du, K.E. Leslie, and C.P. Folie, "Connectivity and limitation of critical current in Bi-Pb-Sr-Ca-Cu/Ag tapes," Phys. Rev. B, vol. 60, pp. 659-66, 1999.

[6] A.A. Polyanskii, M. Feldmann, J. Jiang, X.Y. Cai, S. Patnaik, D.C. Larbalestier, K. Demoranville, D. Yu, and R. Parrella, "Examination of current limiting mechanism in monocore $\mathrm{Ag} / \mathrm{BSCCO}$ tapes with high critical current density," presented at ASC'2000.

[7] H. Yamasaki, K. Endo, S. Kosaka; M. Umeda, S. Misawa; S. Yoshida; K. Kajimura, "Magnetic-field angle dependence of the critical current density in high-quality $\mathrm{Bi}_{2} \mathrm{Sr}_{2} \mathrm{Ca}_{2} \mathrm{Cu}_{3} \mathrm{O}_{\mathrm{x}}$ thin films," IEEE Trans. Appl. Supercond., vol. 3, pp. 1536-1539, 1993.

[8] H. Seino, K. Ishizaki, and M. Takata, "HIPped high density Bi-( $\mathrm{Pb})-$ $\mathrm{Sr}-\mathrm{Ca}-\mathrm{Cu}-\mathrm{O}$ superconductors produced without any additional treatment," Jpn. J. Apl. Phys., vol. 28, pp. L78-L81, 1989.

[9] S.X. Dou, H.K. Liu, M.H. Apperley, K.H. Song, C.C. Sorrell, K.E. Easterling, J. Niska, and S.J. Guo, "Improvement of critical current density in the $\mathrm{Bi}-\mathrm{Pb}-\mathrm{Sr}-\mathrm{Ca}-\mathrm{Cu}-\mathrm{O}$ system through hot isostatic pressing," Physica C, vol. 167, pp. 525-528, 1990.

[10] J.M. Yoo and K. Mukherjee, "The stability of high- $T_{c}$ phase in $\mathrm{Bi}_{1.6} \mathrm{~Pb}_{0.4} \mathrm{Sr}_{2} \mathrm{Ca}_{2} \mathrm{Cu}_{3} \mathrm{O}_{\mathrm{x}}$ compounds prepared by hot isostatic pressing," $J$. Mater. Sci, vol. 28, pp. 2361-2365, 1993

[11] A.J. Bourdilion, N.X. Tan, and C.L. Ong, "Hot isostatically pressed $\mathrm{Bi}_{2} \mathrm{Sr}_{2} \mathrm{Ca}_{2} \mathrm{Cu}_{3} \mathrm{O}_{10}$ coils made with novel precursors," J. Mater Sci. Lett., vol. 15 , pp. 439-441, 1996.

[12] M. Tetenbaum, V.A. Maroni, N.M. Murphy, and S.E. Dorris, "Phase stability domains of $(\mathrm{Bi}, \mathrm{Pb})-2223$ : Data sources, correlation, and assessment," Physica C, vols. 241-248, pp. 497-498, 2000.

[13] R.K. Williams, D.M. Kroeger, P.M. Martin, J.R. Mayotte, E.D. Specht, and J. Brynestad, Effects of high oxygen pressures and temperatures on the stability of the three superconducting Y-Ba-Cu-O compounds," $J$. Appl. Phys., vol. 76, pp. 3673-3678, 1994.

[14] T.R. Thurston, U. Wildgruber, N. Jisrawi, P. Haldar, M. Suenaga, and Y.L. Wang, "Synchrotron z-ray scattering measurements of bulk structural properties in superconducting $\left(\mathrm{Bi}, \mathrm{Pb}_{2}{ }_{2} \mathrm{Sr}_{2} \mathrm{Ca}_{2} \mathrm{Cu}_{3} \mathrm{O}_{10 \cdot x} / \mathrm{Ag}\right.$ tapes," J. Appl. Phys., vol. 79, pp. 3122-3132, 1996. 